\title{
A Synthetic Condition Assessment Model for Power Transformers Using the Fuzzy Evidence Fusion Method
}

\author{
Fenglan Tian ${ }^{1}$, Zhongzhao Jing ${ }^{1}$, Huan Zhao ${ }^{2}$, Enze Zhang ${ }^{2}$ and Jiefeng Liu ${ }^{2, * \mathbb{C}}$ \\ 1 State Grid Zhengzhou Electric Power Supply Company, Zhengzhou 450000, China; fl_tian@126.com (F.T.); \\ xk15578820023@163.com (Z.J.) \\ 2 Guangxi Key Laboratory of Power System Optimization and Energy Technology, Guangxi University, \\ Nanning 530004, China; 1812301052@st.gxu.edu.cn (H.Z.); 1812301049@st.gxu.edu.cn (E.Z.) \\ * Correspondence: liujiefeng9999@163.com; Tel.: +86-1996-812-0257
}

Received: 19 January 2019; Accepted: 1 March 2019; Published: 5 March 2019

\begin{abstract}
Condition-based maintenance decision-making of transformers is essential to electric enterprises for avoiding financial losses. However, precise transformer condition assessment was tough to accomplish because of the negligence of the influence of bushing and accessories, the difficulty of fuzzy grade division, and the lack of reasonable fuzzy evidence fusion method. To solve these problems, a transformer assessing model was proposed in the paper. At first, an index assessing system, considering the main body, the bushing and the accessories components, was established on the basis of components division of transformers. Then, a Cauchy membership function was employed for fuzzy grades division. Finally, a fuzzy evidence fusion method was represented to handle the fuzzy evidences fusion processes. Case studies and the comparison analysis with other methods were performed to prove the effectiveness of this model. The research results confirm that the proposed model could be recommendation for condition based maintenance of power transformers for electric enterprises.
\end{abstract}

Keywords: power transformers; fuzzy information; information fusion; evidential reasoning; condition assessment; condition based maintenance decision making

\section{Introduction}

Safe operation of electric equipment is the basic guarantee of power supply. According to a report of State Grid, form 2005 to 2010, the proportion of serious failures caused by electric equipment in total failures was $37.10-48.15 \%$ [1]. A large power transformer is one of the key electric equipment in a power system, and its failure is one of the most common causes of power system accident. By conservative estimation, there are more than 30,000 transformers (more than $66 \mathrm{kV}$ ) in China. Their condition and operation life are mostly depended on the actual running environment including load rate, running temperature, family defects, and running time. They may be in good condition, which can unceasingly work without maintenance. Or they may be in poor condition, which will cause a transformer fault or even a severe electrical accident if necessary maintenance is not conducted. If that is the case, conducting traditional transformer maintenance (first major repair in the 10th operation year, and then major repairs in every five years; and minor repairs in every one year) will cause "over repair" or "lack of repair", which will result in large financial losses. Condition based maintenance decision making is an effective method to solve the "over repair" and "below repair" problems. The key of condition based maintenance decision making is condition assessment. Therefore, it is extremely important to evaluate the condition of the key equipment and perform necessary and effective maintenance for electric power enterprises, which will save large financial losses [2,3]. 
A large amount of the literature reported assessing the insulation condition of a transformer, however, precise transformer condition assessment including insulation condition was still tough to accomplish in the recent 10 years. Some methods including insulation dielectric spectrum analysis [4-11], partial discharge method [12,13], and dissolve gas analyses [14-22], were reported to assess the insulation condition of a transformer. The effectiveness of dielectric spectrum analysis and partial discharge method had not been largely demonstrated in practical transformers; by contrast, dissolve gas analyses (DGA) was a helpful and practical method for transformer condition assessment in the past few years. Some DGA related methods, including wavelet-aided support vector machine (SVM) [16], Kohonen self-organizing map [17], autoassociative neural networks and mean shift [18], genetic programming [19], and support vector machines [20], were applied to diagnose the faults of transformers and assess the condition of the transformers. Furthermore, some methods, including PSO (particle swarm optimization)-least squares support vector [21], and least square support vector machine (LSSVM) [22], were used to forecast faults of power transformers based on DGA and assess the future condition of the transformers. However, the achievements of these DGA methods are often limited in their failure classifications of the fault condition; actually, the condition of a power transformer is often somewhere between normal condition and failure condition [23]. Otherwise, transformer condition is usually depended on main body condition (determined by DGA, electrical tests, and oil tests), bushing condition, and accessories condition (according to a survey [24], the proportion of accessory failures, including bushing failures and accessory failures, is about $20-45 \%$ in transformer failures, which is some kind of non-ignorable failure in a transformer). Therefore, the DGA method alone is not enough to assess the condition of transformers precisely. Additionally, the aging mechanism of inner transformer is complex and some attention values of indices are uncertain. To make things worse, different indices may reflect different aspects and support conflicting evidences to condition assessment, which will perplex the assessing problem. Thus, it is difficult to obtain an accurate result when assessing the transformer condition $[23,25]$. To handle these problems, [26] proposed a method of condition assessment for transformers using fuzzy theory, offering a new thinking for transformer condition assessment. However, it does not include the necessary components (bushing and accessories of a transformer) in the assessing index system. In addition, the research only focuses on weight information determination method between indices, without taking the fuzzy evidence fusion and evidence conflicts into account, which will reduce the condition assessing accuracy.

To solve the problems, a new assessing model, based on the fuzzy evidence fusion method, is proposed to evaluate the condition of a transformer in this paper. Some advantages of the model are presented such as the reasonable description of the fuzzy synthetic properties and the outstanding capabilities of evidence reasoning combination. A framework of transformer condition assessment is established in Section 2. Preventive tests of the transformer, which are the fundamental and generally used means representing condition of transformer, including the main body, the bushing and the accessories, are selected for the assessing index system. Fuzzy model and fuzzy evidence fusion are studied to solve the grade fuzzy and evidences conflict problem in Section 3. Cases are studied and analyzed in Section 4. The conclusions are shown in Section 5.

\section{Framework of Transformer Condition Assessment}

\subsection{The Assessing Index System of Transformer Condition Assessment}

Generally, a transformer condition assessment problem is regarded as a multi-index assessment problem because various information of assessing indices is required to be synthesized for assessing the condition of a transformer comprehensively. Whether the condition assessment result is precise or not depends on the accuracy of chosen indices. Thus, the first task is to build up the assessing index system in a reasonable way. Components of transformers, including main body $\left(T_{1}\right)$, bushing $\left(T_{2}\right)$ and accessories $\left(T_{3}\right)$, are selected as the components level of assessing system based on relevant 
standards [26-28]. Parameters of $T_{1}$ and $T_{2}$ are quantitative indices, while $T_{3}$ are formed by qualitative indices. The assessing index system is shown in Figure 1.

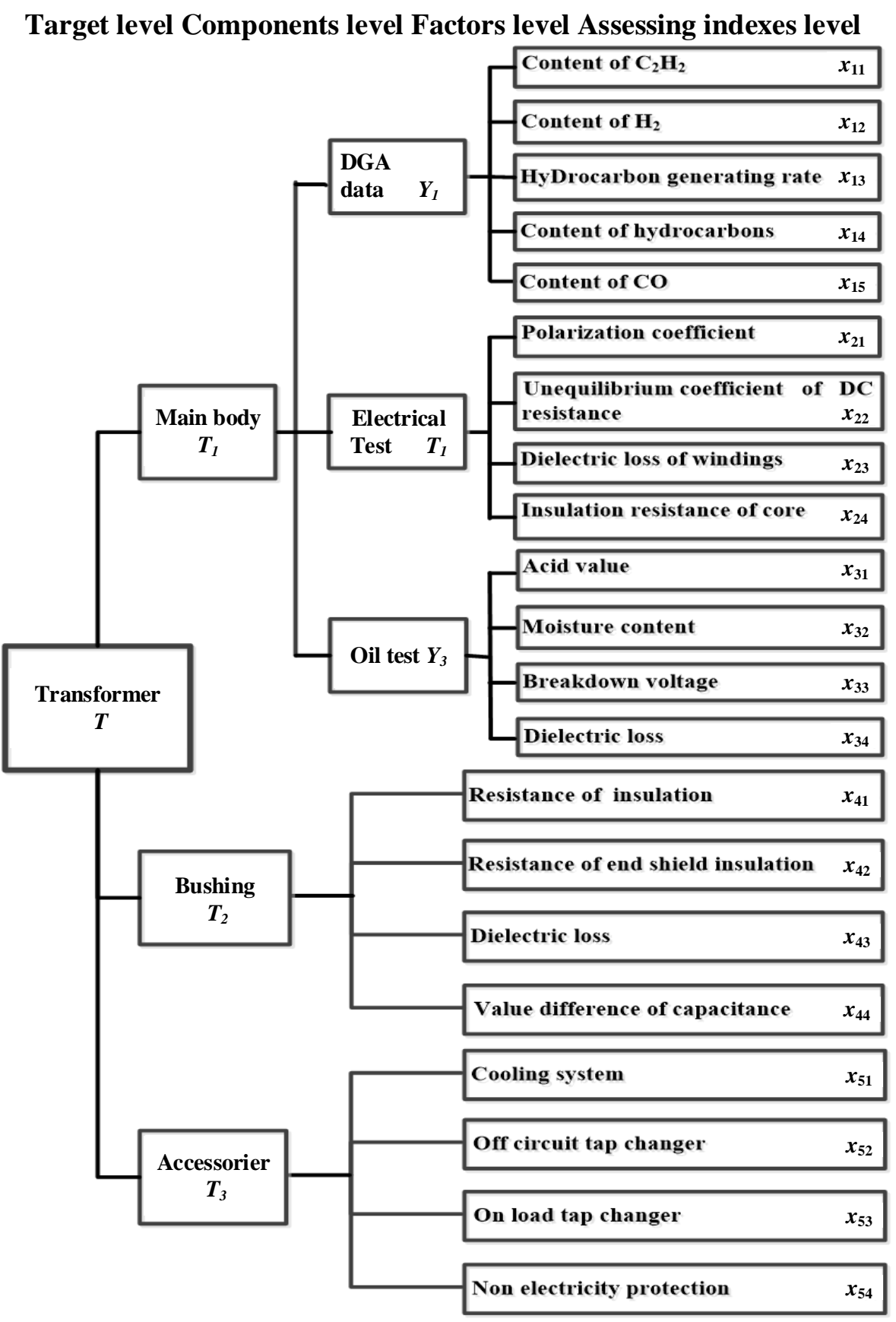

Figure 1. Synthetic assessing index system.

As shown in Figure 1, $T$ is the target layer, which is the assessing output of the transformer condition. There are three components, including main body $\left(T_{1}\right)$, bushing $\left(T_{2}\right)$, and accessories $\left(T_{3}\right)$, which are defined as the components level in the assessing index system. Unlike $T_{2}$ and $T_{3}, T_{1}$ has its own factors level $Y=\left\{Y_{1}, Y_{2}, Y_{3}\right\}$, which consists of DGA indices, electrical test indices, and oil test indices. Supposing that there are a set of indices $X, X=\left\{x_{1}, \cdots, x_{m}, \cdots, x_{M}\right\}$, which forms the assessing indices level. 


\subsection{Assessing Grade Determination}

Generally speaking, it is difficult to compare the aging degree among indices by the original data because they are in different orders of magnitude and units. To solve the problem, the paper applies (1) and (2) to unify the dimension of the original indices' data. The unified results are called relative inferiority degrees. The relative inferiority degrees range within [0,1], with 1 and 0 representing the life-ending state and the initial state of a transformer, respectively. For the indices (e.g., breakdown voltage and insulation resistance of core) which large values are desired, the relative inferiority degrees of them are calculated by Equation (1). For other indices, like $\mathrm{H}_{2}$ content and $\mathrm{C}_{2} \mathrm{H}_{2}$ content, their relative inferiority degrees are obtained by Equation (2):

$$
\begin{aligned}
& x_{m}=\left(e_{m}-e_{m 0}\right) /\left(e_{m 1}-e_{m 0}\right), e_{m 0} \leq e_{m} \leq e_{m 1} \\
& x_{m}=\left(e_{m 0}-e_{m}\right) /\left(e_{m 0}-e_{m 1}\right), e_{m 1} \leq e_{m} \leq e_{m 0}
\end{aligned}
$$

where $x_{m}$ is the relative inferiority degree of the $m$ th index; $e_{m}$ is the current data value of the $m$ th index; $e_{m 0}$ is the normal value of the $m$ th index, which can be obtained by the manufacturer of the equipment; $e_{m 1}$ is the cautionary value of the $m$ th index, representing the insulation of the $m$ th index is seriously deteriorated.

Appropriate transformer condition classification grades can distinguish different condition of a transformer and provide advantageous foundation for condition based maintenance. The condition grades of power transformers are divided into five grades, including good, normal, attentive, poor, and serious, which are expressed by a matrix $g=\left\{g_{1}, g_{2}, g_{3}, g_{4}, g_{5}\right\}$. The relationships between the values of the relative inferiority degrees (RID), the transformer condition grades (TCG), and condition based maintenance strategies (CBMS) are elaborated in Table 1.

$$
g=\left\{g_{1}, g_{2}, g_{3}, g_{4}, g_{5}\right\}=\{\text { good, normal, attendtive, poor, serious }\}
$$

Table 1. Relationships between relative deterioration degrees, condition grades and maintenance strategies.

\begin{tabular}{cccccc}
\hline \multirow{2}{*}{ Items } & \multicolumn{5}{c}{ TCG } \\
\cline { 2 - 5 } & Good & Normal & Attentive & Poor & Serious \\
\hline RID & {$[0-0.2)$} & {$[0.2-0.4)$} & {$[0.4-0.6)$} & {$[0.6-0.8)$} & {$[0.8-1]$} \\
CBMS & Post repair or extended & Normal cycle & Less than the normal cycle & Sooner & Promptly \\
\hline
\end{tabular}

\section{An Integrated Method Based on Fuzzy Evidence Fusion Method}

\subsection{Fuzzy Function}

Some attention values of indices are uncertain and fuzzy because they are determined by expert experience. Therefore, the fuzzy theory is a reasonable method to handle the transformer condition assessment problem [26]. The border of neighboring condition grades can be seen as an interval according to the fuzzy theory [29]. The Cauchy membership function is formed to obtain the membership degrees based on the relationships among the condition grades, the relative inferiority degrees and the membership degrees. The function and its curve are illustrated in Equations (4) and (5) and Figure 2, respectively.

$$
f(x)=1 /\left[1+a\left(x-c_{k}\right)^{b}\right], k=1,2,3,4,5,6
$$




$$
\begin{aligned}
& f_{1}(x)=\left\{\begin{array}{l}
1 \\
\frac{1}{1+a \times\left(x-c_{1}\right)^{b}} \\
0
\end{array}\right. \\
& 0 \leq x \leq c_{1} \\
& c_{1}<x<c_{2} \\
& c_{2} \leq x \leq 1 \\
& f_{2}(x)=\left\{\begin{array}{l}
\frac{1}{1+a \times\left(x-c_{2}\right)^{b}} \\
\frac{1}{1+a \times\left(x-c_{3}\right)^{b}} \\
0
\end{array}\right. \\
& 0 \leq x \leq c_{1} \\
& c_{1}<x \leq c_{2} \\
& c_{2}<x \leq c_{3} \\
& c_{3}<x<c_{4} \\
& c_{4} \leq x \leq 1 \\
& f_{3}(x)=\left\{\begin{array}{l}
\frac{1}{1+a \times\left(x-c_{4}\right)^{b}} \\
\frac{1}{1+a \times\left(x-c_{5}\right)^{b}} \\
0
\end{array}\right. \\
& 0 \leq x \leq c_{3} \\
& c_{3}<x<c_{4} \\
& c_{4} \leq x \leq c_{5} \\
& c_{5}<x<c_{6} \\
& f_{4}(x)=\left\{\begin{array}{l}
\frac{1}{1+a \times\left(x-c_{6}\right)^{b}} \\
\frac{1}{1+a \times\left(x-c_{7}\right)^{b}} \\
0
\end{array}\right. \\
& c_{6} \leq x \leq 1 \\
& 0 \leq x \leq c_{5} \\
& c_{5}<x<c_{6} \\
& c_{6} \leq x \leq c_{7} \\
& c_{7}<x<c_{8} \\
& c_{8} \leq x \leq 1 \\
& f_{5}(x)=\left\{\begin{array}{l}
0 \\
\frac{1}{1+a \times\left(x-c_{8}\right)^{b}} \\
1
\end{array}\right. \\
& 0 \leq x \leq c_{7} \\
& c_{7}<x<c_{8} \\
& c_{8} \leq x \leq 1
\end{aligned}
$$

Experts' experience is that transformer condition grades were averagely divided into five grades according to the relative deterioration degrees in Table 1. As shown in Figure 2, the area between each two condition grades is the fuzzy area, which is described by Cauchy distribution membership. The index value (measured by the relative inferiority degrees) of the intersection points of the 1st (good grade) and the 2nd condition grade, the 2nd and the 3rd condition grade, the 3rd and the 4th condition grade, the 4 th and the 5 th condition grade (serious grade) are $0.2,0.4,0.6,0.8$, respectively. In each intersection point, the membership degree of belongs to the two condition grades is 0.5 . The membership functions are established by rectangular distribution membership and Cauchy distribution membership. The 1st and the 5th condition grade are different from the other grades because of the boundary influence, in which the 1st condition grade tends to be a smaller Cauchy distribution while the 5 th condition grade tends to be a larger Cauchy distribution. According to experts' experience, within the \pm 0.05 range between two intersection points the fuzzy degree is bigger than other fuzzy areas, and the closer to the intersection point, the bigger is the degree. The five fuzzy areas are set to be $[0.15,0.25],[0.35,0.45],[0.55,0.65]$, and [0.75, 0.85]. Therefore, by experts' experience and function resolving, the Cauchy membership function parameters are obtained as the following: $c_{1}=0.15, c_{2}=0.25, c_{3}=0.35, c_{4}=0.45, c_{5}=0.55, c_{6}=0.65, c_{7}=0.75, c_{8}=0.85, b=8, a=1 / 0.058$.

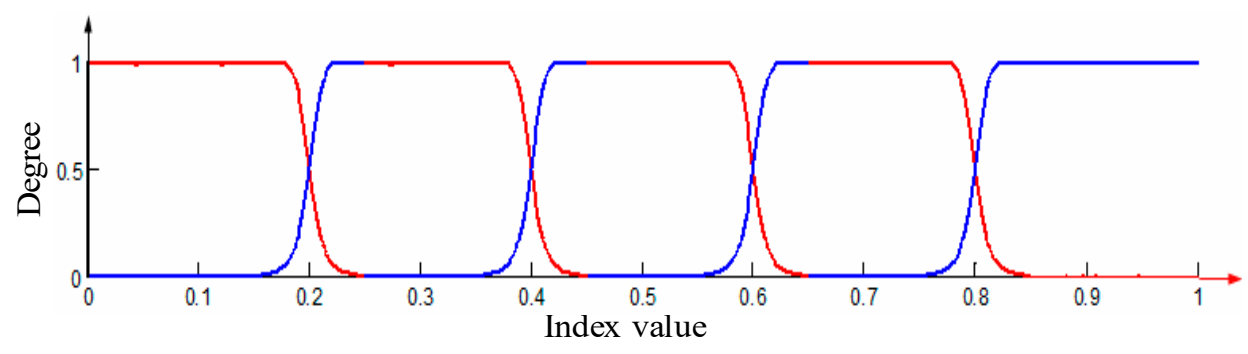

Figure 2. The curve of Cauchy membership function. 


\subsection{Condition Assessment Based on Fuzzy Evidence Fusion Method}

The fuzzy theory is an effective method to solve a multi-index assessment problem [30]. However, the evidence conflicts of multi-index assessment problem should be handled, otherwise the assessing result of the transformer will tend to be a wrong assessment. The advantage of the fuzzy synthetic evidential reasoning method is handling evidence conflicts problems with fuzziness and uncertainty, which makes the proposed method to be an effective tool for processing the fuzzy evidence fusion.

Suppose there is a finite set $\Theta$, which is formed by all independent possible solutions or hypotheses of the proposition; there are basic hypotheses $G n$ and $G n \Theta$, and all possible hypotheses of form a set $G=\left\{G_{1}, G_{2}, \ldots, G_{N}\right\}$, which constitutes the power set $2 \theta$. For example, the conditional level of a transformer is divided into $n(n=5)$ levels in this paper; an additional grade $G(n+1),\{G(n+1)=$ $G(\Theta)\}$, is established to demonstrate the uncertainties of each grade; these six grades can be seen as a set $G$, and $G=\{G 1, G 2, \ldots, G(n+1)\}$.

Supposing that function $m(\Lambda)$ is the basic probability of $\Lambda$, which is the subset of the identified frame $\Theta$; it means that $m(\Lambda)$ describes the extent to which the evidence supports the occurrence of the proposition. Furthermore, the complete belief $\Lambda$ of all propositions within the recognition framework is equal to 1 , and there is no belief in the empty set $\Phi$. As a special space within the set $m(\Theta)$ is defined as describing the uncertainty of $\Lambda$, and in this case, its value can be calculated as the probability that the evaluation result falls within the uncertainty level $G_{(n+1)}$.

Generally, $m(\Lambda)$ satisfies:

$$
\begin{gathered}
\sum_{\Lambda \subseteq \Omega} m(\Lambda)=1, \quad 0 \leq m(\Lambda) \leq 1, \quad m(\Phi)=0 \\
m(\Lambda)=\sum_{T_{1} \cap T_{2} \cap \cdots \cap T_{h}=\psi} \frac{m_{1}\left(T_{1}\right) \cdot m_{2}\left(T_{2}\right) \cdots m_{M}\left(T_{M}\right)}{1-K}, m(\Phi)=0 \\
K=\sum_{T_{1} \cap T_{2} \cap \cdots \cap T_{h}=\Phi} m_{1}\left(T_{1}\right) \cdot m_{2}\left(T_{2}\right) \cdots m_{M}\left(T_{M}\right)
\end{gathered}
$$

The combination algorithm is extended in the following analysis for calculation purposes.

Evidence results can be obtained by the following equations, when combining the (s)th and the $(s+1)$ th evidence.

$$
\begin{aligned}
& \left\{G_{1}\right\}: m_{(s+1)}^{1}=k_{(s+1)}\left(m_{(s)}^{1} m_{s+1}^{1}+m_{(s)}^{1} m_{s+1}^{\Theta}+m_{(s)}^{\Theta} m_{s+1}^{1}\right) \\
& \left\{G_{n}\right\}: m_{(s+1)}^{n}=k_{(s+1)}\left(m_{(s)}^{n} m_{s+1}^{n}+m_{(s)}^{n} m_{s+1}^{\Theta}+m_{(s)}^{\Theta} m_{s+1}^{n}\right) \\
& \left\{G_{\Theta}\right\}: m_{(s+1)}^{\Theta}=m_{(s+1)}=k_{(s+1)} m_{(s)}^{\Theta} m_{s+1}^{\Theta} \\
& k_{(s+1)}+\left[1-\sum_{i=1}^{n+1} m_{(s+1)}^{n+1}\right]^{-1}
\end{aligned}
$$

Each index has different impact on the assessment system, in another word, the weights of the indices are different. Some have notable impact, while others have weak impact, therefore different weights must be assigned to different indices. The Analytic Hierarchy Process (AHP) is a method developed by Saaty in 1980 to support multi-criteria decision making. Since AHP is a helpful tool to assign weights based on expert experience [31], weights of indices and factors were calculated by AHP and shown in Table 2. Taking weights calculation of indices $B 1, B 2$, and $B 3$ for example, the calculating process can be shown as follows:

1. The obtaining of pairwise comparison matrices $A(k)$ 
The pairwise comparisons between the $\mathrm{m}$ decision criteria can be obtained by asking the five experts questions such as which index is more important and what is the decision score (scale 1-9) by Table 2 [26].

Table 2. The AHP scales (1-9) for pairwise comparisons.

\begin{tabular}{cc}
\hline Experts' Score & Definition \\
\hline 1 & Equal importance \\
3 & Moderate importance of one over another \\
5 & Strong importance of one over another \\
7 & Very strong importance of one over another \\
9 & Extreme importance of one over another \\
$2,4,6,8$ & Intermediate values \\
Reciprocals & Reciprocals for inverse comparison \\
\hline
\end{tabular}

The five pairwise comparison matrices of indices $B 1, B 2$, and $B 3$ decided by the five experts can be shown as follows:

$$
A_{B}{ }^{(1)}=\left\{\begin{array}{ccc}
1 & \frac{1}{2} & \frac{1}{3} \\
2 & 1 & \frac{1}{3} \\
3 & 3 & 1
\end{array}\right\} A_{B}{ }^{(2)}=\left\{\begin{array}{ccc}
1 & \frac{1}{3} & \frac{1}{3} \\
3 & 1 & 1 \\
3 & 1 & 1
\end{array}\right\} A_{B}{ }^{(3)}=\left\{\begin{array}{ccc}
1 & \frac{1}{2} & \frac{1}{4} \\
2 & 1 & \frac{1}{2} \\
4 & 2 & 1
\end{array}\right\} A_{B}{ }^{(4)}=\left\{\begin{array}{ccc}
1 & \frac{1}{4} & \frac{1}{5} \\
4 & 1 & \frac{1}{2} \\
5 & 2 & 1
\end{array}\right\} A_{B}{ }^{(5)}=\left\{\begin{array}{ccc}
1 & \frac{1}{3} & \frac{1}{4} \\
3 & 1 & \frac{1}{2} \\
4 & 2 & 1
\end{array}\right\}
$$

2. The calculation of pairwise comparison matrices $B(k)$

$$
B^{(k)}=\lg A^{(k)}=\left[\lg A_{i j}^{(k)}\right]_{m \times m} B^{(k)}=\left[b_{i j}^{(k)}\right]_{m \times m} b_{i j}=\frac{1}{r} \sum_{k=1}^{n} b_{i j}^{(k)},(i, j=1, \ldots, m) B=\left[b_{i j}\right]_{m \times m}
$$

where $n$ is the number of the experts, $m$ is the number of the indices; $n=5, m=3$ in the example.

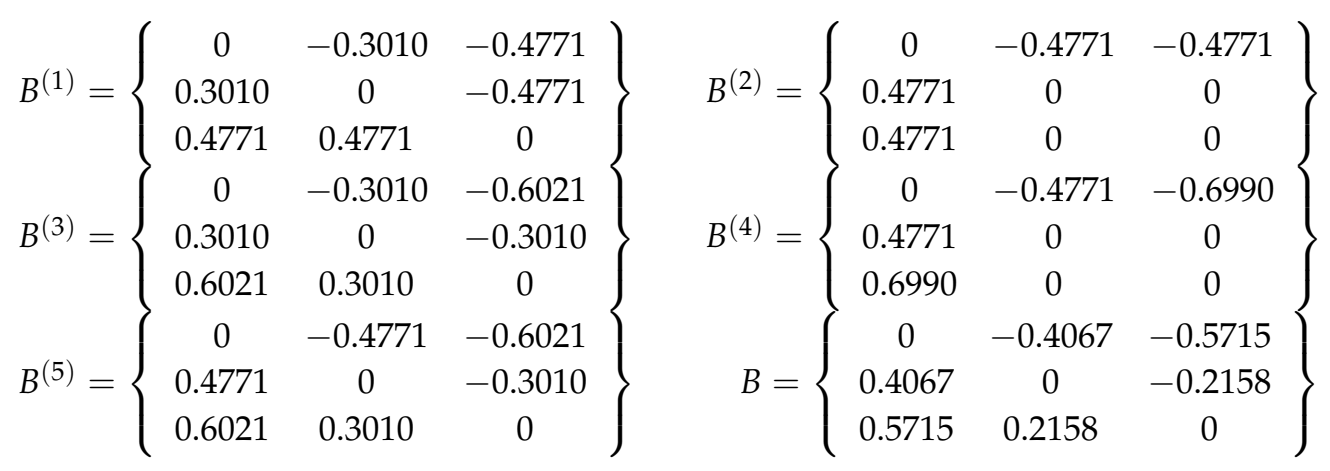

3. The calculation of consistency judgment matrix $S$

The matrix $S$ is the consistency judgment matrix which reflects the overall standard deviation of expert evaluation. If all the matrix elements of matrix $S$ are less than 1 , the weight evaluation of the five experts (measured by five pairwise comparison matrices) is consistent.

$$
\begin{gathered}
s_{i j}=\sqrt{\frac{1}{r-1} \sum_{t=1}^{r}\left[b_{i j}^{(k)}-\frac{1}{r} \sum_{t=1}^{r} b_{i j}^{(k)}\right]^{2}} S=\left[s_{i j}\right]_{m \times m} \\
S=\left\{\begin{array}{ccc}
0 & 0.1297 & 0.0948 \\
0.1297 & 0 & 0.2097 \\
0.0948 & 0.2097 & 0
\end{array}\right\}
\end{gathered}
$$


4. The calculation of weight matrices $w_{b}$ :

$$
c_{i j}=\frac{1}{n} \sum_{k=1}^{n}\left(b_{i k}-b_{j k}\right),(i, j=1, \ldots, m), C=\left[c_{i j}\right]_{m \times m^{\prime}} w_{i j}^{*}=10^{c_{i j}}=10^{\frac{1}{n} \sum_{k=1}^{n}\left(b_{i k}-b_{j k}\right)}, W^{*}=\left[w_{i j}^{*}\right]_{m \times m}
$$

where $w_{b}$ is the characteristic root of matrix $W^{*}$ and denotes the weights of indices $B 1, B 2$, and $B 3$.

$$
\begin{aligned}
& C=\left\{\begin{array}{ccc}
0 & -1.2190 & -1.7904 \\
1.2190 & 0 & -0.5715 \\
1.7904 & 0.5715 & 0
\end{array}\right\} \quad W^{*}=\left\{\begin{array}{lll}
1.0000 & 0.3924 & 0.2530 \\
2.5487 & 1.0000 & 0.6449 \\
3.9520 & 1.5506 & 1.0000
\end{array}\right\} \\
& w_{b}=\left\{\begin{array}{lll}
0.1325 & 0.3378 & 0.5297\}
\end{array}\right.
\end{aligned}
$$

The five pairwise comparison matrices of some indices (not all the pairwise comparison matrices can be shown in the paper limited by the length) are shown as follows:

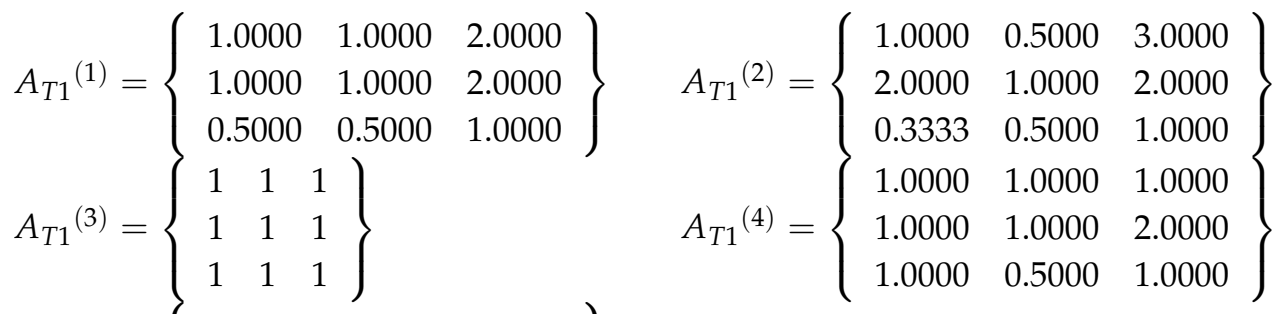

$$
\begin{aligned}
& A_{T 1}{ }^{(5)}=\left\{\begin{array}{lll}
1.0000 & 1.0000 & 2.0000 \\
1.0000 & 1.0000 & 2.0000 \\
0.5000 & 0.5000 & 1.0000
\end{array}\right\} \\
& A_{Y 1}{ }^{(1)}=\left\{\begin{array}{lllll}
1.0000 & 2.0000 & 2.0000 & 1.0000 & 1.0000 \\
0.5000 & 1.0000 & 1.0000 & 0.5000 & 0.5000 \\
0.5000 & 1.0000 & 1.0000 & 0.5000 & 0.5000 \\
1.0000 & 2.0000 & 2.0000 & 1.0000 & 4.0000 \\
1.0000 & 2.0000 & 2.0000 & 0.2500 & 1.0000
\end{array}\right\} \\
& A_{Y 1}{ }^{(2)}=\left\{\begin{array}{lllll}
1.0000 & 3.0000 & 3.0000 & 1.0000 & 2.0000 \\
0.3333 & 1.0000 & 1.0000 & 0.3333 & 0.5000 \\
0.3333 & 1.0000 & 1.0000 & 0.3333 & 0.5000 \\
1.0000 & 3.0000 & 3.0000 & 1.0000 & 5.0000 \\
0.5000 & 2.0000 & 2.0000 & 0.2000 & 1.0000
\end{array}\right\} \\
& A_{Y 1}{ }^{(3)}=\left\{\begin{array}{lllll}
1.0000 & 2.0000 & 2.0000 & 1.0000 & 2.0000 \\
0.5000 & 1.0000 & 1.0000 & 0.5000 & 0.2500 \\
0.5000 & 1.0000 & 1.0000 & 0.5000 & 0.2500 \\
1.0000 & 2.0000 & 2.0000 & 1.0000 & 5.0000 \\
0.5000 & 4.0000 & 4.0000 & 0.2000 & 1.0000
\end{array}\right\} \\
& A_{Y 1}{ }^{(4)}=\left\{\begin{array}{lllll}
1.0000 & 1.0000 & 1.0000 & 0.5000 & 2.0000 \\
1.0000 & 1.0000 & 1.0000 & 0.5000 & 0.2500 \\
1.0000 & 1.0000 & 1.0000 & 0.5000 & 0.2500 \\
2.0000 & 2.0000 & 2.0000 & 1.0000 & 4.0000 \\
0.5000 & 4.0000 & 4.0000 & 0.2500 & 1.0000
\end{array}\right\}
\end{aligned}
$$




$$
A_{Y 1}{ }^{(5)}=\left\{\begin{array}{lllll}
1.0000 & 1.0000 & 1.0000 & 0.5000 & 2.0000 \\
1.0000 & 1.0000 & 1.0000 & 0.5000 & 0.5000 \\
1.0000 & 1.0000 & 1.0000 & 0.5000 & 0.5000 \\
2.0000 & 2.0000 & 2.0000 & 1.0000 & 5.0000 \\
0.5000 & 2.0000 & 2.0000 & 0.2000 & 1.0000
\end{array}\right\}
$$

Weights of indices and factors were calculated by AHP and the results are shown in Table 3.

Table 3. Weights of assessing indices.

\begin{tabular}{cccc}
\hline \multirow{2}{*}{ Component } & \multicolumn{2}{c}{ Items } \\
\cline { 2 - 4 } & Weights & Weights & Weight of Component Indices \\
\hline & & $(0.3974) Y_{1}$ & $\{0.1150,0.2375,0.3566,0.1750,0.1150\}$ \\
Main body $T_{1}$ & 0.5297 & $(0.3665) Y_{2}$ & $\{0.2381,0.2057,0.2287,0.3275\}$ \\
& & $(0.2361) Y_{3}$ & $\{0.1718,0.1974,0.4295,0.2014\}$ \\
Bushing $T_{2}$ & 0.3378 & $T_{2}$ & $\{0.2381,0.2287,0.4264,0.1722\}$ \\
Accessories $T_{3}$ & 0.1325 & $T_{3}$ & $\{0.2163,0.1793,0.3520,0.2524\}$ \\
\hline
\end{tabular}

Evidential reasoning method is an effective method to fuse the index information with equal weight. If this method is extended to fuse the index information with different weights, a revision of the original fuzzy assignment matrix (obtained by the proposed fuzzy function) must be processed after obtaining the original fuzzy assignment matrix and before combining fuzzy information evidences. The revision processing equations can be obtained by (13)-(23):

$$
\begin{gathered}
\bar{w}_{m}=w_{m} / w_{k} \\
\alpha_{m}=\alpha_{k} \bar{w}_{m} \\
x_{m}(H)=\alpha_{m} X_{m}(H) \\
x_{m}(\Theta)=1-\alpha_{m}
\end{gathered}
$$

where $w_{m}=\left\{w_{1}, \cdots, w_{M}\right\}$ is a uniform weight vector; $w_{K}\left(w_{K}=\max \left\{w_{1}, \cdots, w_{M}\right\}\right)$ is the most important index in the index level; $\alpha_{m}(m=1, \ldots, M)$ is a belief degree coefficient; $\alpha_{K}\left(\alpha_{K}=0.95\right)$ is a prior coefficient, representing the largest belief degree factor in the assessment; $X_{m}(H)$ is the original basic assignment probability of index $X_{m} ; X_{m}(H)$ is the revised basic assignment probability; $X_{m}(\Theta)$ is uncertainty of belief assignment. The more important an index is, the more it contributes to evidence combination, which agrees with practical situation.

Not only the information of the indices' weights should be included, but also the evidences' conflict should be considered in the presented method, for the target of precisely assessment. However, evidence conflictions were handled by giving conflicts to the uncertain grade in former studies [20], which made the uncertain space too large to assess the transformer condition precisely. Unlike the former researchers, this paper proposes a new approach to reduce the conflicts of two evidences by Equations (17)-(23). In the assessing model, the partial conflicts are main problems of evidence combination, because the membership degrees of different indices are significantly different. For calculating the partial conflicts between the two evidences $x_{a}\left(G_{n}\right)$ and $x_{b}\left(G_{n}\right)$, suppose that con represents the partial conflicts between the two evidences, $r\left(x_{a}, x_{b}\right)$ is the relationship of the two evidences, and con $=0.75$ in this paper. If $0 \leq c o n<0.75$, meaning the conflict is acceptable, the classic evidential reasoning approach is still available. If $0.75 \leq c o n$, meaning the conflict of the two evidences 
is too large that the classic evidential reasoning approach fails. Evidences Rectifications should be handled according to the equations:

$$
\begin{aligned}
& x_{a}\left(G_{n}\right)=\left[a_{1} \cdots a_{n}\right], \quad x_{b}\left(G_{n}\right)=\left[b_{1} \cdots b_{n}\right] \\
& G_{x_{b}}\left(x_{a}\right)=\sum_{n=1}^{m} b_{n} \times e^{\left(-5 \times a_{n}\right)} \\
& G\left(x_{a}\right)=\sum_{n=1}^{m} b_{n} \times e^{\left(-5 \times b_{n}\right)} \\
& G\left(x_{a}, x_{b}\right)=G_{x_{a}}\left(x_{b}\right)+G_{x_{b}}\left(x_{a}\right) \\
& r\left(x_{a}, x_{b}\right)=G\left(x_{a} \otimes x_{b}\right) / G\left(x_{a}, x_{b}\right)=\left(G\left(x_{a}\right)+G\left(x_{b}\right)\right) /\left(G_{x_{a}}\left(x_{b}\right)+G_{x_{b}}\left(x_{a}\right)\right) \\
& \text { con }_{h}=1-r\left(x_{a}, x_{b}\right) \\
& \beta_{h}=\sqrt{\frac{\gamma}{\operatorname{con}_{h}}}
\end{aligned}
$$

where $\mathrm{con}_{h}$ represents the partial conflict degree between the $(h)$ th index evidence and the the $(h+1)$ th index evidence; $\beta_{h}$ is an intermediate variable, which can represents the conflict degree.

When the $(h)$ th index evidence $m_{h, n}\left(G_{n}\right)$ is combining with the $(h+1)$ th index evidence $m_{h+1, n}\left(G_{n}\right)$, the rectified evidences of the $(h)$ th and the $(h+1)$ th grades can be obtained based on Equations (19) to (22). The combination result can be seen in Equation (23):

$$
\begin{gathered}
m_{h, n}^{1}\left(G_{n}\right)=\beta_{h} \times m_{h, n}\left(G_{n}\right)(n=1,2, \cdots, 5) \\
m_{h, n+1}^{1}\left(G_{\Theta}\right)=m_{h, n+1}^{1}\left(G_{n+1}\right)=1-\beta_{h}+\beta_{h} \times m_{h, n+1}\left(G_{n+1}\right) \\
m_{h+1}^{1}\left(G_{n}\right)=\beta_{h} \times m_{h+1, n}\left(G_{n}\right) \\
m_{h+1, n+1}^{1}\left(G_{\Theta}\right)=m_{h+1, n+1}^{1}\left(G_{n+1}\right)=1-\beta_{h}+\beta_{h} \times m_{h+1, n+1}\left(G_{n+1}\right) \\
m_{(h)}^{1}=m_{h}^{1}\left(G_{n}\right) \oplus m_{h+1}^{1}\left(G_{n}\right)
\end{gathered}
$$

The original basic probability assignment results of factors' evidences are obtained after combining the index evidence one by one. Suppose $F_{s}(G)$ is the original basic probability assignment of factor $f_{s}$; $f_{\mathcal{S}}(G)$ is the revised basic probability assignment; $f_{\mathcal{S}}(\Theta)$ is the belief assignment of uncertainty; and are the adjusted evidences of the $(s)$ th and the $(s+1)$ th factors respectively. After combining all the factors' evidential information, the total assessment of one component (e.g., main body) can be obtained by Equation (24):

$$
F_{(s)}^{1}=f_{s}^{1}\left(G_{n}\right) \oplus f_{s+1}^{1}\left(G_{n}\right)
$$

The evidential reasoning criterion for determining transformer condition grades is shown in Equations (25):

$$
\left\{\begin{array}{c}
m_{S}\left(G_{N 0}\right)>m_{S}\left(G_{\Theta}\right) \\
m_{S}(\Theta)<\varepsilon
\end{array}\right.
$$

where $\left.m_{s}\left(G_{N 0}\right)=\max \left\{m_{s}\left(G_{n}\right)\right\}, G_{n} \subseteq G, n=1,2, \cdots, N\right\} ; m_{s}(\Theta)$ is the belief degree value of uncertainty grade $G(n+1) ; \varepsilon(\varepsilon=0.05)$ is the threshold value according to expert experience. The less value of $\varepsilon$ is desirable, which means the precise and reliable assessing result. The flowchart of the condition assessment method using fuzzy evidence fusion method can be summarized by Figure 3 . 


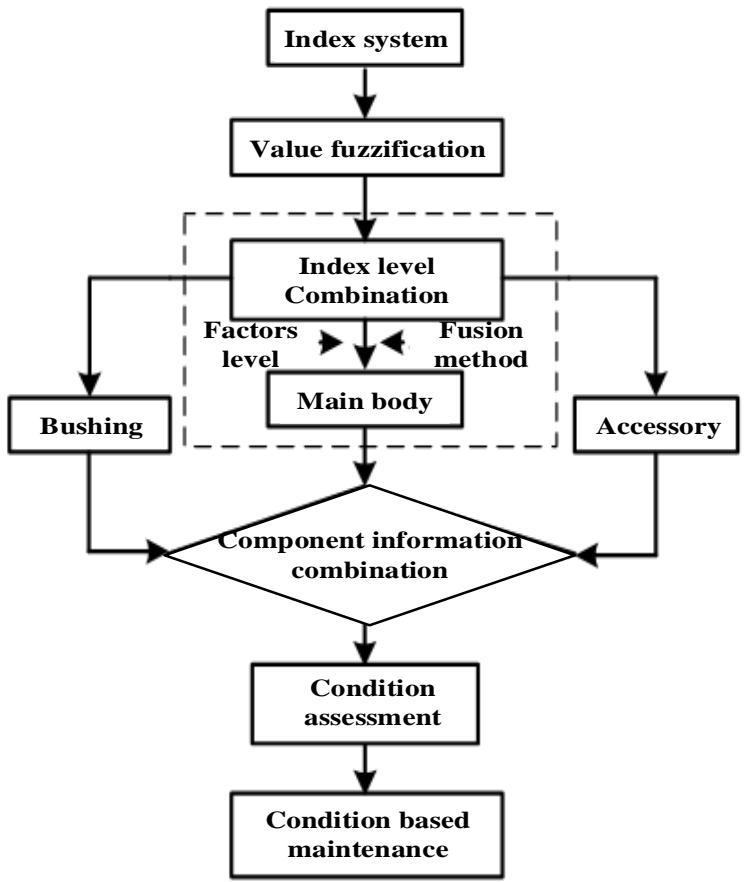

Figure 3. The flowchart of transformer condition assessment.

\section{Case Study}

\subsection{Case 1}

The preventative test data of a $220 \mathrm{kV}$ transformer, which were acquired from an electric power company in 2009, are shown in Table 4.

Table 4. Transformer preventive test results.

\begin{tabular}{ccc}
\hline & \multicolumn{2}{c}{ Testing Dates } \\
\cline { 2 - 3 } Testing Items & $\mathbf{2 0 0 9 - 0 3 - 0 5}$ & $\mathbf{2 0 0 9 - 0 8 - 1 8}$ \\
\hline $\mathrm{H}_{2}(\mu \mathrm{L} / \mathrm{L})$ & 9.200 & 9.700 \\
$\mathrm{C}_{2} \mathrm{H}_{4}(\mu \mathrm{L} / \mathrm{L})$ & 33.900 & 81.700 \\
$\mathrm{CH}_{4}(\mu \mathrm{L} / \mathrm{L})$ & 19.200 & 46.000 \\
$\mathrm{C}_{2} \mathrm{H}_{6}(\mu \mathrm{L} / \mathrm{L})$ & 97.500 & 164.300 \\
$\mathrm{C}_{2} \mathrm{H}_{2}(\mu \mathrm{L} / \mathrm{L})$ & 0 & 0.100 \\
$\mathrm{CO}(\mu \mathrm{L} / \mathrm{L})$ & 16 & 56 \\
$\mathrm{CO}_{2}(\mu \mathrm{L} / \mathrm{L})$ & 456 & 540 \\
Total hydrocarbons $(\mu \mathrm{L} / \mathrm{L})$ & 4.170 & 8.760 \\
Polarization coefficient & $/$ & $4.586 \%$ \\
The relative generating rate of total hydrocarbons & 2.000 & 1.770 \\
Dielectric loss of winding $(\%)\left(20{ }^{\circ} \mathrm{C}\right)$ & 0.390 & 0.350 \\
Disequilibrium coefficient of $\mathrm{DC}$ resistance $(\%)$ & 0.410 & 0.360 \\
insulation resistance $(\mathrm{M} \Omega)$ & 10,000 & 11,000 \\
Moisture content in oil $(\mathrm{mg} / \mathrm{L})$ & 12.530 & 12.640 \\
Breakdown voltage $(\mathrm{kV})$ & 50 & 50 \\
Dielectric loss of oil $\left(90{ }^{\circ} \mathrm{C}\right)$ & 0.019 & 0.001 \\
Acid value $(\mathrm{mg}(\mathrm{KOH}) / \mathrm{g})$ & 0.005 & 0.009 \\
Resistance of bushing $(\mathrm{M} \Omega)$ & 70,000 & 70,000 \\
End-shield resistance $(\mathrm{M} \Omega)$ & 50,000 & 50,000 \\
Dielectric loss of bushing $\left(20^{\circ} \mathrm{C}\right)$ & 0.200 & 0.200 \\
Initial value difference of capacitance $(\%)$ & -2.890 & -2.002 \\
\hline
\end{tabular}


The following information was obtained from the transformer maintenance log: the cooling device surface was covered by some dust, the oil level was abnormal.

The condition assessment of the transformer can be performed according to the test data. First, according to relevant historical data, the relative generating rate of total hydrocarbons (RGRTH) can be calculated as $4.586 \%$. To obtain the index value of the accessories, the indices' relative inferiority degrees should be calculated by employing the experts' experience standards and the deductive method [32,33]. Specifically speaking, for factor layer $Y_{1}$, the relative inferiority degree is calculated by (1) or (2) and represented; calculating results are shown as follow: $\left\{x_{1}=0, x_{2}=0.0647, x_{3}=0.4586\right.$, $\left.x_{4}=0.0584, x_{5}=0.1600\right\}$. The fuzzy judgment matrix of membership degree, calculated by the Cauchy distribution function, of each part is given in Equation (26):

$$
X_{1}=\left[\begin{array}{lllll}
Y_{1} 0.0000 & 0.0647 & 0.4586 & 0.0584 & 0.1600 \\
Y_{2} 0.1150 & 0.1800 & 0.4375 & 0.0000 & \\
Y_{3} 0.5056 & 0.5714 & 0.0320 & 0.0900 & \\
T_{2} 0.0000 & 0.0000 & 0.0200 & 0.4004 & \\
T_{3} 0.0600 & 0.0000 & 0.0600 & 0.0400 &
\end{array}\right]
$$

Based on $X_{1}$, the membership degree between the indices and the grades can be calculated by Equations (4) and (5), and the results are shown in Table 5.

Table 5. Calculation of membership degree.

\begin{tabular}{cccccc}
\hline \multirow{2}{*}{ Membership Degree } & \multicolumn{5}{c}{ Assessing Grade } \\
\cline { 2 - 6 } & $g_{1}$ & $g_{\mathbf{2}}$ & $g_{3}$ & $g_{4}$ & $g_{5}$ \\
\hline$x_{11}$ & 1.0000 & 0 & 0 & 0 & 0 \\
$x_{12}$ & 1.0000 & 0 & 0 & 0 & 0 \\
$x_{13}$ & 0 & 0 & 1.0000 & 0 & 0 \\
$x_{14}$ & 1.0000 & 0 & 0 & 0 & 0 \\
$x_{15}$ & 0.9911 & 0.0089 & 0 & 0 & 0 \\
$x_{21}$ & 1.0000 & 0 & 0 & 0 & 0 \\
$x_{22}$ & 0.9394 & 0.0606 & 0 & 0 & 0 \\
$x_{23}$ & 0 & 0.0111 & 0.9889 & 0 & 0 \\
$x_{24}$ & 1.0000 & 0 & 0 & 0 & 0 \\
$x_{31}$ & 0 & 0 & 1.0000 & 0 & 0 \\
$x_{32}$ & 0 & 0 & 0.9745 & 0.0255 & 0 \\
$x_{33}$ & 1.0000 & 0 & 0 & 0 & 0 \\
$x_{34}$ & 1.0000 & 0 & 0 & 0 & 0 \\
\hline
\end{tabular}

To calculate the main body $\left(T_{1}\right)$ condition, using the calculation results from Table 4 , the weight information in Table 2 and Equations (13)-(23), an assignment matrix of main body is obtained and shown in Equations (27):

$$
G\left(T_{1}\right)=\left[\begin{array}{cccccc}
g_{1} & g_{2} & g_{3} & g_{4} & g_{5} & g_{\Theta} \\
0.5557 & 0.0004 & 0.3544 & 0 & 0.00 & 0.0895 \\
0.9757 & 0.0007 & 0.0147 & 0 & 0.00 & 0.0089 \\
0.8304 & 0.0000 & 0.0986 & 0.0011 & 0.0 & 0.0699
\end{array}\right]
$$

In order to obtain the result of the transformer condition assessment, Equations (13)-(24) are used to synthesize the factors condition information, which can be seen in matrix (28). After combining evidences of all three components $(G(T)$ in Equation (29)), the total condition of the transformer is shown in the matrix in Equation (30).

$$
G_{\text {body }}=\left[\begin{array}{llllll}
0.9265 & 0.0001 & 0.0520 & 0.0000 & 0 & 0.0214
\end{array}\right]
$$




$$
\begin{gathered}
G(T)=\left[\begin{array}{cccccc}
g_{1} & g_{2} & g_{3} & g_{4} & g_{5} & g_{\Theta} \\
0.9265 & 0.0001 & 0.0520 & 0.0 & 0.0 & 0.0214 \\
0.0508 & 0.0074 & 0.8412 & 0.0066 & 0 & 0.0939 \\
0.9966 & 0.0000 & 0.0000 & 0.0000 & 0 & 0.0034
\end{array}\right] \\
G_{\text {total }}=\left[\begin{array}{llllll}
0.8632 & 0.0004 & 0.1082 & 0.0003 & 0 & 0.0280
\end{array}\right]
\end{gathered}
$$

The assessment result can be obtained by using criterion (25) to the result of Equation (30). The conclusion is that the transformer condition is grade $g_{1}$. No fault happens in that transformer. The condition based maintenance is suggested to be prolonged. Other information can be analyzed from the result: the main body and the accessories of the transformer are in good condition, while the bushing is on the attentive condition, hence the condition based maintenance of the bushing is that preventing tests should be operated ahead of normal schedule. Practically, the transformer is in good condition. Only cleaning of insulation waste on the bottom of oil tank was carried out in the maintenance log. It can be concluded that the assessing result of the transformer is reasonable.

\subsection{Case 2}

The body data, the operational history, and the maintenance records of the transformer in [23] were selected and calculated by Equations (1) or (2), the relative inferiority degree of the indices and the calculation results of membership degree were shown in Equation (31) and Table 6.

$$
X_{1}=\left[\begin{array}{lllll}
Y_{1} 0.6400 & 0.6140 & 0.6200 & 0.6020 & 0.5629 \\
Y_{2} 0.8000 & 0.2750 & 0.7375 & 0.3750 & \\
Y_{3} 0.1000 & 0.8400 & 0.6286 & 0.6025 & \\
T_{2} 0.0000 & 0.0200 & 0.6000 & 0.0400 & \\
T_{3} 0.3000 & 0.0000 & 0.5000 & 0.0000 &
\end{array}\right]
$$

Table 6. Calculation of the membership degree.

\begin{tabular}{cccccc}
\hline \multirow{2}{*}{ Membership Degree } & \multicolumn{5}{c}{ Assessing Grade } \\
\cline { 2 - 6 } & $g_{1}$ & $g_{2}$ & $g_{3}$ & $g_{4}$ & $g_{5}$ \\
\hline$x_{11}$ & 0 & 0 & 0.0089 & 0.991 & 0 \\
$x_{12}$ & 0 & 0 & 0.1156 & 0.8844 & 0 \\
$x_{13}$ & 0 & 0 & 0.0606 & 0.9394 & 0 \\
$x_{14}$ & 0 & 0 & 0.4209 & 0.5791 & 0 \\
$x_{15}$ & 0 & 0 & 0.9885 & 0.0115 & 1.0000 \\
$x_{21}$ & 0 & 0 & 0 & 0.5000 & 0.5000 \\
$x_{22}$ & 0 & 1.0000 & 0 & 0 & 0 \\
$x_{23}$ & 0 & 0 & 0 & 1.0000 & 0 \\
$x_{24}$ & 0 & 0.9637 & 0.0363 & 0 & 0 \\
$x_{31}$ & 1.0000 & 0 & 0 & 0 & 0 \\
$x_{32}$ & 0 & 0 & 0 & 0.0089 & 0.9911 \\
$x_{33}$ & 0 & 0 & 0.0255 & 0.9745 & 0 \\
$x_{34}$ & 0 & 0 & 0.4017 & 0.5983 & 0 \\
$x_{41}$ & 1.0000 & 0 & 0 & 0.5000 & 0 \\
$x_{42}$ & 1.0000 & 0 & 0 & 0 & 0 \\
$x_{43}$ & 0 & 0 & 0.5 & 0 & 0 \\
$x_{44}$ & 1.0000 & 0 & 0 & 0 & 0 \\
$x_{51}$ & 0 & 1.000 & 0 & 0 & 0 \\
$x_{52}$ & 1.0000 & 0 & 0 & 0 & 0 \\
$x_{53}$ & 0 & 0 & 1.0000 & 0 & 0 \\
$x_{54}$ & 1.0000 & 0 & 0 & 0 & 0 \\
\hline & & & & & \\
\hline & 0 & 0 & 0 & 0 \\
\hline
\end{tabular}


To calculate the main body $\left(T_{1}\right)$ condition, using the calculation results in Table 5 , the weight information in Table 2 and the Equations (13)-(23), an assignment matrix of main body is obtained and shown in Equation (32):

$$
G(T)_{1}=\left[\begin{array}{cccccc}
g_{1} & g_{2} & g_{3} & g_{4} & g_{5} & g_{\Theta} \\
0.0000 & 0.0000 & 0.0697 & 0.8229 & 0.0000 & 0.1074 \\
0.0000 & 0.7658 & 0.0165 & 0.1795 & 0.0000 & 0.0382 \\
0.0270 & 0.0000 & 0.0374 & 0.8491 & 0.0338 & 0.0528
\end{array}\right]
$$

In order to obtain the result of the transformer condition assessment, Equations (13)-(24) are used to synthesize the factors condition information, which can be seen in the matrix in Equation (33). After combining evidences of all three components $(G(T)$ of Equation (34)), the total condition of the transformer is shown in the matrix in Equation (35).

The assessment result can be obtained by using the criterion of Equation (25) to the result of Equation (35). The conclusion is that the transformer condition is grade $g_{4}$. The condition based maintenance is that testing should be done sooner for the transformer. Actually, the sealing between the top of the oil tank and bushing coupler is not tight, which causes the transformer insulation in the high moisture condition.

$$
\begin{aligned}
& G_{\text {body }}=\left[\begin{array}{lllllll}
0.0014 & 0.1580 & 0.0234 & 0.7678 & 0.0018 & 0.0477
\end{array}\right] \\
& G(T)_{1}=\left[\begin{array}{ccccccc}
g_{1} & g_{2} & g_{3} & g_{4} & g_{5} & g_{\Theta} \\
0.0014 & 0.1580 & 0.0234 & 0.7678 & 0.0018 & 0.0477 \\
0.3278 & 0.0000 & 0.3023 & 0.3023 & 0.0000 & 0.0675 \\
0.3120 & 0.0564 & 0.5349 & 0.0000 & 0.0000 & 0.0967
\end{array}\right] \\
& G_{\text {total }}=\left[\begin{array}{llllll}
0.0229 & 0.1385 & 0.0596 & 0.7149 & 0.0015 & 0.0627
\end{array}\right] \\
& G_{\text {body } 1}=\left[\begin{array}{llllll}
0.2179 & 0.2850 & 0.1810 & 0.3011 & 0.0150 & 0.000
\end{array}\right] \\
& G_{\text {body } 2}=\left[\begin{array}{llllll}
0.1170 & 0.1391 & 0.2106 & 0.2714 & 0.2619 & 0.0
\end{array}\right] \\
& G_{\text {body3 } 3}=\left[\begin{array}{llllll}
0.0011 & 0.2445 & 0.3432 & 0.34725 & 0.0336 & 0.0304
\end{array}\right]
\end{aligned}
$$

For further study, the assessing results of main body in by using fuzzy evidence fusion, fuzzy theory [26], set pair theory [34], and classic evidential reasoning method [35] (without considering conflicts of information) are calculated and shown in Equations (33), (36)-(38), respectively.

By applying fuzzy theory, the evidences supported by grades of $g_{2}$ and $g_{4}$ are proximally the same and hard to distinguish efficiently. By using set pair theory, the evidences supported by grades of $g_{4}$ and $g_{5}$ are proximally the same. By using evidential reasoning method, the assessing results support grades of $g_{3}$ and $g_{4}$ are almost the same. In other words, these situations often lead to a mistaken assessment when assessing the condition of the main body. In contrast, the proposed method supports the $g_{4}$ grade clearly, and the result is more reasonable than the other three methods based on the practical situation. That is because the suggested method not only considers the fuzziness and the uncertainty of transformer attribute, but also handles the weights and the conflict of different evidences.

Therefore, the two cases demonstrate that the proposed method is an effective method to handle transformer condition assessment problem.

\subsection{Other Cases}

Thirty-nine other transformers in service were selected as assessing samples. The assessing procedure is implemented and conclusion of these samples is shown in Table 7.

Based upon the statistical results that have mentioned the total accuracy hits $84.6 \%$. It demonstrates the validity of the integrated model. The table shows that the proposed method achieves 
the best performance when the actual condition of the transformer is $g_{1}$ or $g_{5}$ (the assessing accuracy hits more than $87.5 \%$ ). Additionally, it achieves good performance when the transformers are in $g_{3}$ and $g_{4}$ (the assessing accuracy is $85.7 \%$ and 80 , respectively). However, the assessing accuracy is only $75 \%$ when assessing the middle class. This is because fuzziness and uncertainty is always the largest one in the middle grade.

Table 7. Assessing result of transformers.

\begin{tabular}{cccccc}
\hline \multirow{2}{*}{ Results } & $g_{1}$ & $g_{2}$ & $g_{3}$ & $g_{4}$ & $g_{5}$ \\
\cline { 2 - 6 } & 11 & 7 & 8 & 5 & 8 \\
Number of samples & 10 & 6 & 6 & 4 & 7 \\
Correct results & 90.9 & 85.7 & 75.0 & 80 & 87.5 \\
Accuracy (\%) & \multicolumn{5}{c}{84.6} \\
\hline Total accuracy (\%) &
\end{tabular}

\section{Conclusions}

A synthetic condition assessment model for power transformers using fuzzy evidence fusion method is proposed in the study. The conclusions of the reported work are shown as follows:

Comparing with the fuzzy theory, the set pair theory, and the evidential reasoning method, the transformer condition assessing result of the proposed method is more reasonable. That is because both the conflict of evidences and the information of index weights are taken into consideration in the suggested model, which can improve the accuracy of assessment. The proposed model is demonstrated to be an efficient method for assessing the synthetic condition of a transformer and an effective method to provide guidance for CBM of transformers.

Although the proposed method shows an efficient tool to assess the synthetic transformer condition, some disadvantages, including weights determining subjectivity, lacking of new testing technology indices (e.g., moisture of paper, dielectric spectrum analysis, magnitude of partial discharge, and infrared thermometer), and parameters setting subjectivity, will need to be improved in future works.

Author Contributions: In this research activity, all the authors were involved in the data collection and preprocessing phase, model constructing, empirical research, results analysis and discussion, and manuscript preparation. All authors have approved the submitted manuscript.

Funding: This research was funded by the National Natural Science Foundation of China (61473272; 51867003), the Natural Science Foundation of Guangxi (2018JJB160056; 2018JJB160064; 2018JJA160176).

Conflicts of Interest: The authors declare no conflict of interest.

\section{References}

1. Zheng, H.B. Study on Condition Assessment and Fault Diagnosis Approaches for Power Transformers. Ph.D. Thesis, Chongqing University, Chongqing, China, 2012.

2. Liao, R.J.; Zhang, Y.Y.; Yang, L.J. A cloud and evidential reasoning integrated model for insulation condition assessment of high voltage transformers. Intern. Trans. Electr. Energy Syst. 2014, 24, 913-926. [CrossRef]

3. Zhang, Y.Y.; Zheng, H.B.; Liu, J.F.; Zhao, J.H.; Sun, P. An Anomaly Identification Model for Wind Turbine State Parameters. J. Clean. Prod. 2018, 195, 1214-1227. [CrossRef]

4. Liu, J.F.; Zheng, H.B.; Zhang, Y.Y.; Wei, H.; Liao, R.J. Grey Relational Analysis for Insulation Condition Assessment of Power Transformers Based Upon Conventional Dielectric Response Measurement. Energies 2017, 10, 1526. [CrossRef]

5. Liu, J.; Fan, X.; Zheng, H.; Zhang, Y.; Zhang, C.; Lai, B.; Wang, J.; Ren, G.; Zhang, E. Aging condition assessment of transformer oil-immersed cellulosic insulation based upon the average activation energy method. Cellulose 2019, 1-18. [CrossRef] 
6. Zhang, Y.Y.; Liu, J.F.; Zheng, H.B.; Wei, H.; Liao, R.J. Study on Quantitative Correlations between the Ageing Condition of Transformer Cellulose Insulation and the Large Time Constant Obtained from the Extended Debye Model. Energies 2017, 10, 1842. [CrossRef]

7. Zheng, H.B.; Liu, J.F.; Zhang, Y.Y.; Ma, Y.J.; Shen, Y.; Zhen, X.C.; Chen, Z.L. Effectiveness analysis and temperature effect mechanism on chemical and electrical-based transformer insulation diagnostic parameters obtained from PDC data. Energies 2018, 11, 146. [CrossRef]

8. Koch, M.; Prevost, T. Analysis of dielectric response measurements for condition assessment of oil-paper transformer insulation. IEEE Trans. Dielectr. Electr. Insul. 2012, 19, 1908-1915. [CrossRef]

9. Zhang, Y.Y.; Liu, J.F.; Zheng, H.B.; Wang, K. Feasibility of a universal approach for temperature correction in frequency domain spectroscopy of transformer insulation. IEEE Trans. Dielectr. Electr. Insul. 2018, 25, 1766-1773. [CrossRef]

10. Saha, T.K.; Purkait, P. Understanding the impacts of moisture and thermal aging on transformer's insulation by dielectric response and molecular weight measurements. IEEE Trans. Dielectr. Electr. Insul. 2008, 15, 568-582. [CrossRef]

11. Liu, J.F.; Zheng, H.B.; Zhang, Y.Y.; Zhou, T.C.; Zhao, J.; Li, J.Q.; Liu, J.Q.; Li, J.C. Comparative investigation on the performance of modified system poles and traditional system poles obtained from PDC data for diagnosing ageing condition of transformers polymer insulation materials. Polymers 2018, 10, 191. [CrossRef]

12. Sina, M.; Mohammadreza, Y.; Mehdi, N. A novel AE based algorithm for PD localization in power transformers. J. Electr. Eng. Technol. 2013, 8, 1487-1496.

13. Wang, K.; Li, J.Z.; Zhang, S.Q.; Liao, R.J.; Wu, F.F.; Yang, L.J.; Li, J.; Grzybowski, S.; Yan, J.M. A Hybrid Algorithm Based on S Transform and Affinity Propagation Clustering for Separation of Two Simultaneously Artificial Partial Discharge Sources. IEEE Trans. Dielectr. Electr. Insul. 2015, 22, 1042-1060. [CrossRef]

14. Liu, J.F.; Zheng, H.B.; Zhang, Y.Y. Dissolved Gases Forecasting Based on Wavelet Least Squares Support Vector Regression and Imperialist Competition Algorithm for Assessing Incipient Faults of Transformer Polymer Insulation. Polymers 2019, 11, 85. [CrossRef]

15. Koley, C.; Purkalt, P.; Chakravorti, S. Wavelet-aided SVM tool for impulse fault identification in transformers. IEEE Trans. Power Del. 2006, 21, 1283-1290. [CrossRef]

16. Da, S.; Ana, C.M.; Castro, A.R.G.; Miranda, V. Transformer failure diagnosis by means of fuzzy rules extracted from Kohonen Self-Organizing Map. Intern. J. Electr. Power Energy Syst. 2012, 43, 1034-1042.

17. Miranda, V.; Garcez, C.; Adriana, R.; Lima, S. Diagnosing Faults in Power Transformers with Autoassociative Neural Networks and Mean Shift. IEEE Trans. Power Deliv. 2012, 27, 1350-1357. [CrossRef]

18. Shintemirov, A.; Tang, W.; Wu, Q.H. Power Transformer Fault Classification Based on Dissolved Gas Analysis by Implementing Bootstrap and Genetic Programming. IEEE Trans. Syst. Man Cybern. Part C Appl. Rev. 2009, 39, 69-79. [CrossRef]

19. Bacha, K.; Souahlia, S.; Gossa, M. Power transformer fault diagnosis based on dissolved gas analysis by support vector machine. Electr. Power Syst. Res. 2012, 83, 73-79. [CrossRef]

20. Huang, X.G.; Zhang, Y.Y.; Liu, J.F. A novel fault diagnosis system on polymer insulation of power transformers based on 3-stage GA-SA-SVM OFC selection and ABC-SVM classifier. Polymers 2018, 10, 1096. [CrossRef]

21. Zheng, H.B.; Zhang, Y.Y.; Liu, J.F.; Wei, H.; Zhao, J.H.; Liao, R.J. A novel model based on wavelet LS-SVM integrated improved PSO algorithm for forecasting of dissolved gas contents in power transformers. Electr. Power Syst. Res. 2018, 155, 196-205. [CrossRef]

22. Fang, J.K.; Zheng, H.B.; Liu, J.F.; Zhao, J.H.; Zhang, Y.Y.; Wang, K. A Transformer Fault Diagnosis Model Using an Optimal Hybrid Dissolved Gas Analysis Features Subset with Improved Social Group Optimization-Support Vector Machine Classifier. Energies 2018, 11, 1922. [CrossRef]

23. Tahani, H.; Keller, J.M. Information fusion in computer vision using the fuzzy integral. IEEE Trans. Syst. 1990, 20, 733-741. [CrossRef].

24. Wang, Z.G. Power Transformer Components Failure Analysis and Improvement; China Electric Power Press: Beijing, China, 2010.

25. Tang, W.H.; Spurgeon, K.; Wu, Q.H.; Richardson, Z.J. An evidential reasoning approach to transformer condition assessments. IEEE Trans. Power Deliv. 2004, 19, 1696-1703. [CrossRef]

26. Liao, R.J.; Wang, Q.; Luo, S.J.; Liao, Y.X.; Sun, C.X. Condition Assessment Model for Power Transformer in Service Based on Fuzzy Synthetic Evaluation. Autom. Electr. Power Syst. 2008, 32, 70-75. 
27. IEEE Guide for the Evaluation and Reconditioning of Liquid Immersed Power Transformers; IEEE Std. C57.140-2006; IEEE New York Monitor: New York, NY, USA, 27 April 2007.

28. IEEE Guide for the Interpretation of Gases Generated in Oil-Immersed Transformers; IEEE Std.C57.104-2008; IEEE: New York, NY, USA, 2 February 2009.

29. Zadeh, I.A. Fuzzy sets. Inf. Control 1965, 8, 338-353. [CrossRef]

30. Yager, R.R. On the Dempster-Shafer framework and new combination rules. Inf. Sci. 1987, 41, 93-138. [CrossRef]

31. Saaty, T.L. The Analytic Hierarchy Process; McGraw-Hill: New York, NY, USA, 1980.

32. Regulations of Condition-Based Maintenance \& Test for Electric Equipment; China State Grid Corporation Standard; Q/GDW 168-2008; China Electric Power Press: Beijing, China, 2008.

33. Zhang, Y.Y. Study on Life Cycle Cost based Maintenance Decision Making for Power Transformers Considering Condition Assessment and Insulation Life Assessment. Master's Thesis, Chongqing University, Chongqing, China, 2014.

34. Liao, R.J.; Zheng, H.B.; Yang, L.J.; Zhang, Y.Y.; Huang, F.L.; Sun, C.X. A Power Transformer Insulation Condition Assessment Method based on Set Pair Analysis. Autom. Electr. Power Syst. 2010, 34, 55-60.

35. Liao, R.J.; Zheng, H.B.; Stanislaw, G.; Yang, L.J.; Zhang, Y.Y.; Liao, Y.X. An integrated decision-making model for condition assessment of power transformers using fuzzy approach and evidential reasoning. IEEE Trans. Power Del. 2011, 26, 11111-11117. [CrossRef]

(C) 2019 by the authors. Licensee MDPI, Basel, Switzerland. This article is an open access article distributed under the terms and conditions of the Creative Commons Attribution (CC BY) license (http://creativecommons.org/licenses/by/4.0/). 